\title{
The speciation of fluorine in phosphogypsum.
}

\author{
NAOURES HMISSI, DHIMAZ GALIH PRASETYO, \\ ERZSÉBET HARMAN-TÓTH AND TAMÁS GÁBOR \\ WEISZBURG
}

Eötvös Loránd University

Presenting Author: hmissinaoures@gmail.com

Phosphogypsum (PG) is a by-product of the fertilizer industry. It is generated by attacking natural phosphate rock (PR) with sulphuric acid $\left(\mathrm{H}_{2} \mathrm{SO}_{4}\right)$ to obtain phosphoric acid $\left(\mathrm{H}_{3} \mathrm{PO}_{4}\right)$.

$\mathrm{PG}$ is a heterogeneous aggregated mixture, its main component is gypsum, but contains also quartz, bassanite, brushite, the partly soluble malladrite $\left(\mathrm{Na}_{2} \mathrm{SiF}_{6}\right)$, fluorite $\left(\mathrm{CaF}_{2}\right)$, some organic matter $(\mathrm{OM})$ and clay minerals as well. The utilisation of PG is hindered by the presence of some radioactive elements, fluorine, potentially toxic metals and phosphorus. Leaching tests revealed that the most problematic elements in PG are $\mathrm{F}$ and $\mathrm{P}$, classifying it as hazardous waste. In this study of a mainland-deposited Tunisian PG we intend to quantitatively specify to which phases is fluorine linked. Previous leaching tests show that the water-leachable fluorine content is $500-1000$ ppm while the total F-content of PG is on the 10000 ppm order of magnitude. Main F-phases could be fluorite, malladrite, clay minerals (with $\mathrm{F}$ replacing $\mathrm{OH}$ groups) and maybe, also $\mathrm{OM}$ could adsorb some F.

Some PG grains $(<5 \%)$ are black, rich in organic matter. However, most of PG grains are colorless with less organic matter content. Approximately $10 \%$ of these grains showed varying fluorescence color under the $365 \mathrm{~nm}$ UV light (yellow, white, orange).

XPD confirmed that the major phase is gypsum and the minor phases are quartz (inherited from PR rock) and bassanite. Malladrite is also present occasionally. Clay phases were detected with basal distances of 14 and $15 \AA$.

SEM-EDS showed that gypsum is present in elongated prismatic habit and quartz in rounded shape with a size range of 80-110 $\mu \mathrm{m}$. Both were also present as fine-grained material. Further identified phases are sulphides (pyrite, Cd-sphalerite) with a size range 7-18 $\mu \mathrm{m}$ and iron-phosphate. Fluorite was found as octahedral or cubooctahedral crystals, in the size range $5-20 \mu \mathrm{m}$, fine-grained material and also in globular shape.

The F-content of the clay mineral fraction and the OM-rich black grains will be studied.

This work was completed in the ELTE Institutional Excellence Program (TKP2020-IKA-05), financed by the Hungarian Ministry of Human Capacities, and was supported by the Koch Sándor Foundation. 